\author{
JULIETA ORTIZ GAITÁN
}

\title{
La casa sede del Instituto de Investigaciones Estéticas en la ciudad de Oaxaca
}

$\mathrm{E}$ N I875, El ViAjERo ALEMÁn Friedrich Ratzel, al aproximarse a la ciudad de Oaxaca, quedó impresionado de manera "agradable y bienhechora” y fascinado con la belleza del valle que jamás había visto en región alguna, "a excepción de los altiplanos en los alrededores cercanos a la ciudad de México". Ya en la ciudad, la llamada Antequera por el emperador Carlos V, se percató de la huella destructora causada por guerras y terremotos al encontrar "cientos de casas vacías y derruidas, al igual que los conventos", I por lo que la primera vista que tuvo de la ciudad era de "una arquitectura de modesta sencillez y claridad que todavía da a la ciudad actual una personalidad equilibrada y tranquila”. ${ }^{2}$ Todo ello confería al conjunto una visión horizontal, con numerosos solares, huertos y campos de cultivo, donde destacaban imponentes, aquí y allá, las cúpulas y torres de iglesias y conventos virreinales.

Hay ciertamente un consenso entre los autores que han estudiado el patrimonio arquitectónico de la ciudad de Oaxaca al afirmar que son escasas las

I. Francisco José Ruiz Cervantes, "La ciudad de Oaxaca en I 875”, en Sebastián van Doesburg et al., Teobert Maler: vistas de Oaxaca, I 874-1876, Oaxaca, Casa de la Ciudad, 2006, p. I 2 (los fuertes sismos de que se tiene memoria ocurrieron en I 845, I 854, I 870 y I 872); Carlos Antonio de Jesús Lira Vázquez, "La ciudad de Oaxaca. Una aproximación a su evolución urbana decimonónica y al desarrollo arquitectónico porfiriano”, tesis de maestría en Restauración de Monumentos, México, Universidad Nacional Autónoma de México-Facultad de Arquitectura, I997, p. 97.

2. Lira Vázquez, op. cit., p. 33. 
edificaciones que pueden fecharse en los siglos XVI y XVII debido principalmente a la acción devastadora de los terremotos y a la constante situación de guerra iniciada con la independencia de la Corona española, lo que condujo a un siglo xix caótico y violento tanto por las luchas internas entre liberales y conservadores como por las batallas libradas contra la intervención extranjera. Así, la mayoría de las casonas que subsisten hasta nuestros días ha sufrido un intenso proceso de remodelación y reconstrucción que debe tomarse en cuenta en el momento del estudio y el rescate histórico.

El trazo urbano, que data del siglo Xvi, se adelantó cerca de 40 años a las ordenanzas para la planeación de las ciudades promulgadas por Felipe II en I573. De cómo se inició y fue configurándose la apariencia de la población, sabemos que

las construcciones se levantaron lentamente en los principios del siglo XvI, pero aumentaron rápidamente después de I 550 para satisfacer las necesidades de una población creciente. Las primeras edificaciones, que incluían casas particulares, iglesias y edificios públicos, fueron hechas casi sistemáticamente de adobe con techos de paja; quienes pudieron afrontar el gasto construyeron sus casas de piedra obtenida de canteras cercanas, las construcciones de piedra aumentaron hacia fines del siglo, pero el adobe no perdió su popularidad. ${ }^{3}$

Más tarde, en octubre de 1794, el intendente Antonio de Mora y Feysal, por orden del virrey Branciforte, dividió la ciudad en cuarteles mayores y menores, lo que al parecer no alteró significativamente su fisonomía, ya que John K. Chance asegura que un plano de 1777 demuestra que el trazado de las calles y la ubicación de los edificios públicos eran esencialmente los mismos que en 1978, cuando él publica su estudio. La ciudad cambió poco y conservó su traza reticular dividida en cuarteles para efectos administrativos; las casas más relevantes por su construcción pertenecían a los españoles y al clero o eran edificios gubernamentales y se ubicaban en calles embaldosadas cercanas a la catedral y a la plaza principal; no obstante, la mayoría presentaba una factura modesta en calles de tierra con deficiencia en los servicios públicos.

La principal fuente económica consistió en la explotación de la grana cochinilla, empleada como colorante en la obtención del hermoso y peculiar

3. John K. Chance, Race and Class in Colonial Oaxaca, apud Robert James Mullen, La arquitectura y la escultura de Oaxaca I 530-I980, vol. I: La ciudad de Oaxaca, México, Codex, 1992, p. I32. 
bermellón tan común en las artesanías mexicanas, pero también destacaron los oficios de maestros canteros, alfareros y talabarteros, entre otros, así como el auge del comercio propiciado por el porfiriato.

Robert James Mullen, por su parte, afirma que en la ciudad de Oaxaca "dar una fecha segura para un edificio no religioso es absolutamente imposible". ${ }^{4}$ De acuerdo con lo anterior, puede afirmarse que los ejemplos más representativos de arquitectura civil que se ven actualmente en la zona central de la ciudad de Oaxaca datan del siglo xviII en adelante, la mayoría desarrollados a partir de un programa arquitectónico original con plantas virreinales y porfirianas, adaptado a los cambios y las modificaciones que el transcurrir del tiempo y la vida fueron demandando.

\section{Los avatares de una casa}

En la manzana ubicada entre la avenida Independencia al norte, Hidalgo hacia el sur, calle de León al oriente frente a la Alameda y avenida 20 de Noviembre al poniente, se encuentra una antigua casona, sede de los institutos de Matemáticas y de Investigaciones Estéticas de la Universidad Nacional Autónoma de México. Esta casa ha sufrido diversas alteraciones causadas, en parte, por las sucesivas operaciones de compraventa que la modificaron y que unieron su destino a los nuevos propietarios; el más relevante, sin duda, monseñor Eulogio Gregorio Gillow y Zavalza, primer arzobispo de Oaxaca, estableció ahí la casa arzobispal con fachada a la avenida Independencia, en el número 37.

Desde los primeros registros hasta la fecha quedó asentado que la integraban varias casas principales, todas con patios interiores que, si bien fragmentados, alterados y con remodelaciones, aún se pueden apreciar en las construcciones actuales. Las tres fachadas más relevantes de la propiedad han sido la de la avenida Independencia, del que fue el Palacio Arzobispal, que ostenta el año de 1895 grabado en un medallón de piedra en el dintel del portón; la de la calle de León, nuestra sede, y la de avenida Hidalgo, una casa donde vemos, grabado en un medallón de su portada el año de 1909.

Nuestra casa se ubica, desde agosto de 2007, en la calle Antonio de León número 2 y colinda con el hotel Monte Albán, en una época llamado hotel 
Nacional, ubicado en la que fue casa de la familia Ortigosa. 5 El registro más antiguo de esta propiedad data de I8I2 y lo proporciona Juan I. Bustamante Vasconcelos cuando menciona que Rafael del Villar y su esposa Josefa Cañedo, ambos españoles, habitaban la casa ubicada en la plazuela de Catedral, sin número, "junto a la casa de Ortigosa hoy hotel Monte Albán". ${ }^{6}$ Originalmente, en el siglo XVI, se proyectaba construir en el predio las casas consistoriales para lo cual el virrey Martín Enríquez de Almanza donó al cabildo de Antequera dos solares situados frente a la catedral; sin embargo, en este lugar se estableció el mercado de alfareros y ahí permaneció durante dos siglos aproximadamente. La plazuela de Catedral fue posteriormente llamada "de Cántaros, porque en ella se hacía el mercado de todas las piezas de alfarería trabajadas por los indios"? En el siglo XVII esta plazuela se llamaba "de Arauxo" o "de la Cruz de Arauxo", nombre ligado seguramente a uno de sus más antiguos vecinos. ${ }^{8}$ Hay que decir que, debido a la disposición arquitectónica de la catedral respecto a la plaza de Armas, la entrada principal se encuentra precisamente frente a esta plazuela, hoy alameda de León, y no hacia la plaza principal.

Recién proclamada la Independencia, la casa fue residencia del Congreso. En I824 se publica en Oaxaca el Acta Constitutiva de la Federación; pero dejemos que Jorge Fernando Iturribaría narre el suceso:

El 8 de febrero de 1824 se publicó en Oaxaca a las cinco de la tarde, por medio de bando solemne, el Acta Constitutiva de la Federación. Era domingo, la ciudad estaba engalanada. El vecindario despertó con el estruendo de los repiques y las salvas. Hubo por la noche iluminación extraordinaria de ocote, pues aún no se establecía el alumbrado público de aceite. Los vecinos manifestaban su regocijo colocando frente a sus respectivos domicilios, a mitad de la calle, anafres de barro convertidos en pequeńas

5. Antes de pertenecer a los Ortigosa, una familia encumbrada de Oaxaca, la casa fue de Bárbara Magro. Véase Hugo Altamirano Ramírez, La ciudad de Oaxaca que conoció Morelos, Oaxaca, s.e., I992, p. 3 I.

6. Juan I. Bustamante Vasconcelos, "Intento de correlación de las diferentes nomenclaturas de la ciudad de Oaxaca, Oax. A partir de 1792 hasta la fecha”, Oaxaca, Fundación Cívico Cultural Bustamante Vasconcelos-Fondo Juan I. Bustamante V., texto mecanografiado, agosto de I982, p. 23.

7. Juan Bautista Carriedo, Estudios históricos y estadísticos del estado oaxaqueño, México, Talleres Gráficos de Adrián Morales, I949, p. 245.

8. Altamirano Ramírez, op. cit., p. 24. 


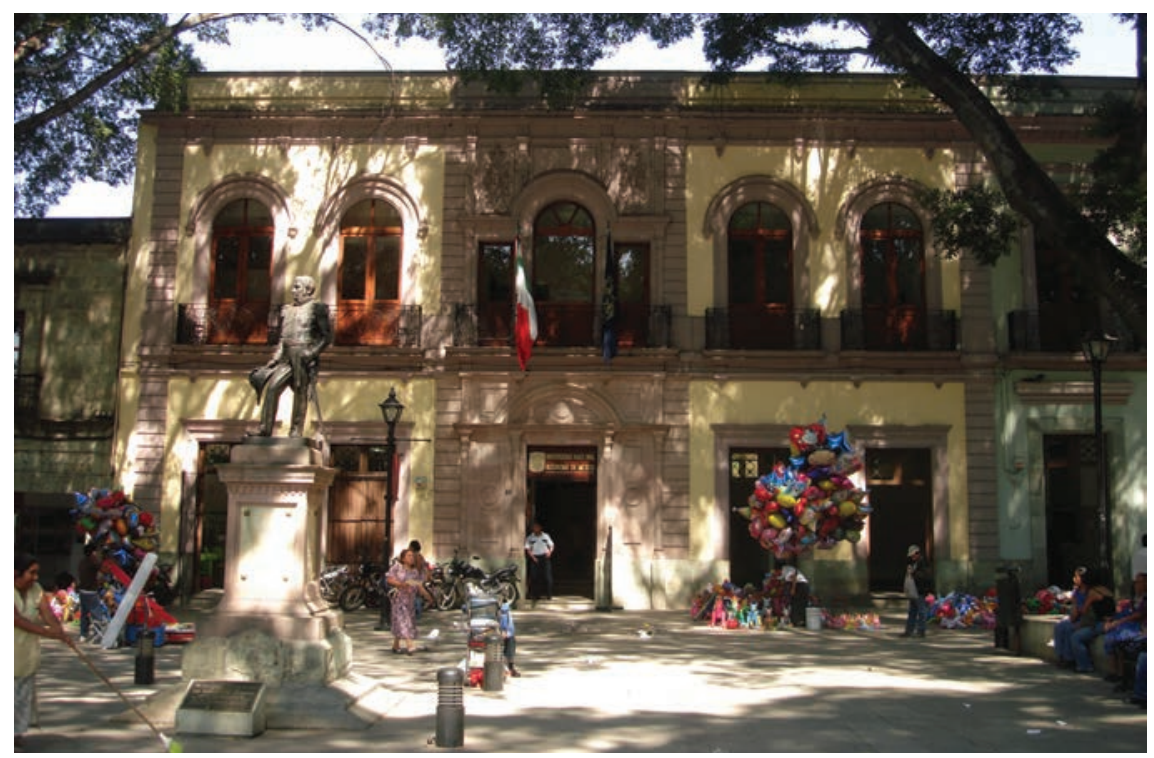

I. Fachada de la casa sede en Oaxaca, frente a la alameda de León. Foto: Marina Bayón, 2007. Archivo Fotográfico Manuel Toussaint, IIE-Unam.

piras. Hubo colgaduras en los balcones y serenata en la plaza, reminiscencias de las extintas fiestas virreinales. ${ }^{9}$

Así festejaba Oaxaca la instauración de la nueva época republicana. En ese tiempo, el Congreso, máxima representación del pueblo, no contaba con un lugar propio para sesionar, ya que desde I823 compartía con el ayuntamiento las antiguas casas consistoriales. A partir de I824, nuestro edificio sede albergaría el Congreso del Estado durante cuatro años, debido a que dichas casas estaban en ruinas.

Los diputados se reunieron en la casa número tres de la plazuela de Catedral donde se había trasladado el Congreso desde febrero de ese año, llegando poco tiempo después el gobernador Murguía y Galardi, el comandante León y el ayuntamiento. Abajo en la plazuela esperaban numerosos caballos que fueron tomados por los funcionarios.

9. Jorge Fernando Iturribaría, Historia de Oaxaca I 82 I-I 854 : de la consumación de la Independencia a la iniciación de la Reforma, Oaxaca, Ramírez Belmar, 1935, p. 35. 
La cabalgata se formó en dos alas para el desfile, que presidieron el gobernador y don José López Ortigosa, presidente del Congreso quien se colocó a la izquierda del Ejecutivo. La tropa de la guarnición hizo los honores, formada en la plaza mientras el pueblo, atónito sobre las azoteas y en los balcones de los edificios, veía esta primera ostentación de nuestras instituciones democráticas. ${ }^{\text {IO }}$

En I832, el Congreso local expidió una disposición para comprar el edificio de las casas consistoriales y reconstruirlo para establecer ahí el Palacio de los Poderes, tarea encomendada al arquitecto Francisco de Paula Heredia, la construcción del Palacio continuó hasta el porfiriato cuando finalmente fue inaugurado el is de septiembre de i883. Esto "Debido a los altibajos económicos, a la inestabilidad política y a los sismos". I I

La casa de la calle de León gozó, desde el inicio, de una ubicación privilegiada, sin duda por estar frente a la entrada principal de la catedral y teniendo de por medio un frondoso y umbrío jardín en la entonces llamada plazuela de Cántaros. En I842, el general Antonio de León transformó este sitio en una "elegante alameda", proyecto del ingeniero Antonio P. Heredia, "hermoso sitio de recreo que no tiene álamos, pero sí muchos fresnos corpulentos que fueron plantados por aquel inolvidable gobernador". Esta primera alameda se encontraba cerrada por una cerca de madera, con una fuente en el centro que todavía puede verse en el plano del conde Antonio Diebitech de Sabalkanski, ${ }^{\text {I2 }}$ y fue inaugurada por el general León el I3 de octubre de I843, antes de partir a encontrarse con su destino en la guerra de intervención estadounidense. El general Antonio de León fue un ciudadano que consagró "su vida entera al servicio de la patria y a quien debe ésta por lo mismo eterna gratitud". Héroe militar de las gestas independentistas, De León tuvo en sus manos tanto el mando militar como el político, hasta que la situación de guerra causada por la invasión lo requirió de nuevo en el campo de batalla, y donde perdió la vida el 8 de septiembre de I847 en el Molino del Rey, en las inmediaciones del bosque de Chapultepec. ${ }^{\text {I3 }}$

Io. Idem.

I I. Lira Vázquez, op. cit., p. 87.

I2. Véase el plano, en Lira Vázquez, op. cit., p. I03 y http://www.lib.utexas.edu/benson/ historicmaps/maps2o.html.

I3. Andrés Portillo, Oaxaca en el Centenario de la Independencia Nacional. Noticias históricas y estadisticas de la ciudad de Oaxaca, y algunas leyendas tradicionales recogidas por Andrés Portillo con 


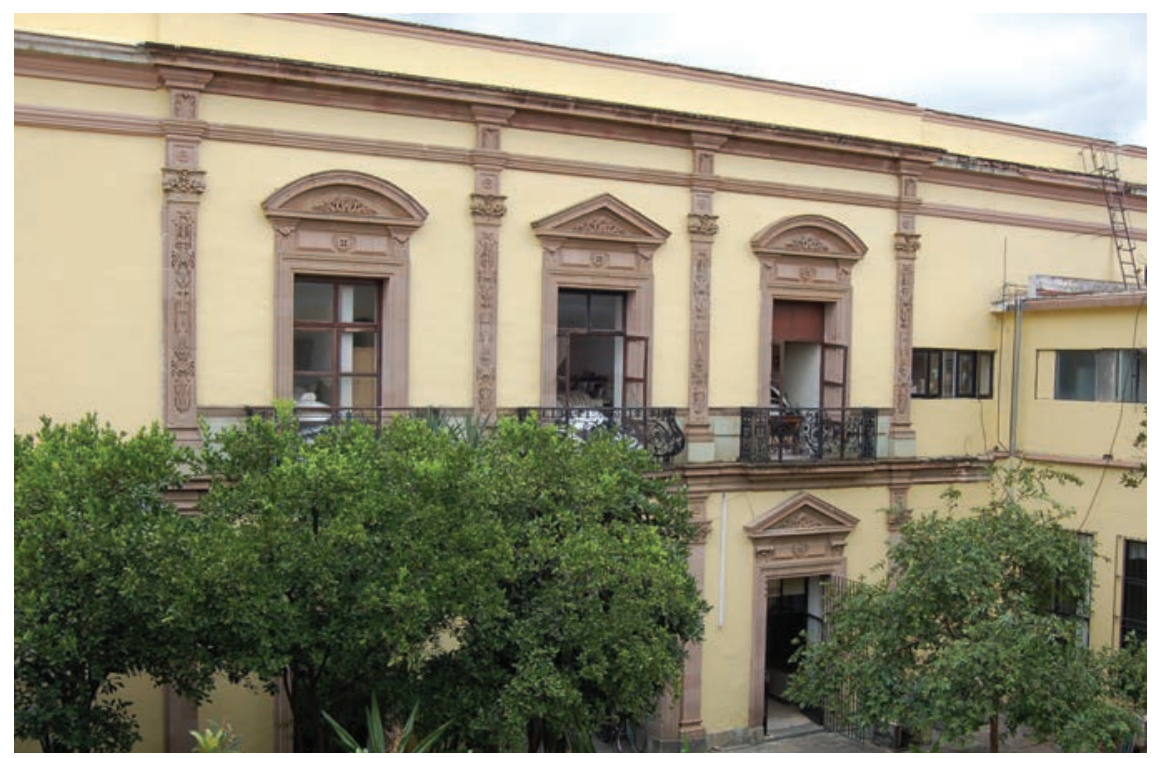

2. Patio interior. Foto: Cecilia Gutiérrez, 2007. Archivo Fotográfico Manuel Touissaint, IIE-UNAM.

Otro general oaxaqueño, que a la larga tuvo una fortuna nada adversa, fue Porfirio Díaz, quien luchó al frente del ejército republicano contra la intervención de Napoleón III y los avances de las tropas del general Bazaine, las cuales devastaron y tomaron por un tiempo la antigua Antequera. Entonces, los templos de Santo Domingo, La Soledad, La Merced y San Francisco fueron utilizados como bastiones defensivos y en el antiguo obispado se instaló un arsenal y la fábrica de pólvora. La ciudad se recuperó a finales de I867.

Resulta fácil imaginar la situación precaria y azarosa que se vivía debido a la guerra, que continuamente asolaba a los habitantes de la ciudad y los dejaba en la incertidumbre e indefensos ante la violencia. El ayuntamiento y el gobierno estatal, a merced de la inestabilidad y el deterioro, se encontraban imposibilitados para ejercer la administración con eficacia, ya que atender a los heridos, enterrar a los muertos y tratar de proteger a los más desvalidos requería ciertamente la atención más urgente. No extraña, pues, que la ciudad ofreciera un aspecto deplorable. Según un diario de la época:

la cooperación de varias personas cuyos nombres constan en los capitulos respectivos, Oaxaca, Imprenta del Estado a cargo de Hipólito Salazar, I9 Io, p. 88. 
Tenemos el sentimiento de manifestar que en esta ciudad la policía se halla en abandono: pocas calles hay que no se encuentren desempedradas [sic] y con escabrosidades [sic], que impiden transitar con franqueza a los carruajes y aun a la gente. Se advierten grandes lodazales ocasionados por la represa de las aguas sucias que salen de las casas. ${ }^{\text {I4 }}$

La recién remozada alameda también entró en un estado de abandono y descuido, poblándose de alimańas como las chintatlahuas, arañas de apariencia temible que, según el mismo diario, habitaban en las grietas de la fuente y de las glorietas cercanas. ${ }^{\mathrm{IS}} \mathrm{A}$ todas estas calamidades hay que agregar los frecuentes sismos, como el terrible de I845 que asoló a la región afectando lo poco que seguía en pie, tuvo que llegar la visión porfiriana de fin de siglo, con su renovado impulso de modernidad, para que la alameda de León fuera transformada en un "jardín de estilo inglés" más a tono con la época. En septiembre de I886, el gobernador del estado, general Luis Mier y Terán, descubrió la estatua del general Antonio León que se alza desde entonces en el centro del parque. ${ }^{16}$ Según otros autores, es desde i 884 cuando la alameda recibe el nombre de alameda de León, como se le conoce en la actualidad. ${ }^{17}$

La casa solariega, cuya fachada da a la sexta calle de avenida Independencia en el número 37 - anteriormente cuarta del Colegio de Niñas-, fue objeto asimismo de una serie de ventas y modificaciones antes de convertirse en el Palacio Arzobispal de Oaxaca. Se menciona que "en el No. 3 de esta calle, donde después se edificó el Palacio Arzobispal, recibió el traidor Picaluga el precio de su felonía por la entrega que hizo del insurgente Guerrero a sus enemigos" ${ }^{\text {I } 8}$

I4. La Cucarda, I 5 de diciembre de I850. apud. Lira Vázquez, op. cit., p. I26.

15. Carlos Lira Vázquez menciona que es común en Oaxaca que las madres, ante las travesuras de sus hijos pequeños, los amenacen con que "ahí viene la chintatlahua", en lugar del conocido y temido "Coco".

I6. Santa Gómez Sarubbi y María del Pilar Cisneros López, "Análisis histórico formal de los jardines el siglo xIx en la ciudad de Oaxaca”, tesis de licenciatura, México, Universidad Autónoma Benito Juárez de Oaxaca-Facultad de Arquitectura, s.f.

I7. En consecuencia, la calle frene a la alameda y de por medio con la casa recibe también el nombre de calle de León a partir de I 884. Véase "Bienes desamortizados según la ley llamada 'Ley Juárez’ del 25 de junio del año de I 856. Lista de bienes desamortizados a instituciones religiosas en las calles de la ciudad de Oaxaca; Nomenclatura de la ciudad de Oaxaca antes del ańo de I 884 comparada con la actual", concentración y notas del C. Fausto Mejía M., Oaxaca, Fundación Cívico Cultural Bustamante Vasconcelos-Fondo Juan I. Bustamante V., texto mecanografiado, agosto de I93 I.

I8. Ángel Taracena, Efemerides oaxaqueñas, Oaxaca, s.e., I 94I, pp. 77 y 78. Se dice que Picaluga recibió “ 3000 onzas de oro” por traicionar al general Vicente Guerrero en I 83 I. 
Las casas y las manzanas aparecen con detalle en el plano de la ciudad que trazó el conde Antonio Diebitech de Sabalkanski en I848, por orden del gobernador del estado, Benito Juárez García, quien mandó elaborar dicho plano para subsanar, en parte, la falta de datos, instrumentos y recursos para la administración pública. En este plano

se pueden distinguir en cada manzana las fachadas de los edificios, el número de niveles que tenían las casas habitación así como sus pretiles; en algunas partes de la ciudad las bardas aparecen como si estuvieran semidestruidas y algunos templos sólo presentan una de sus torres o ninguna; mudos recuerdos tal vez, del denominado sismo de santa Francisca que asoló a Oaxaca en I $845 .{ }^{19}$

Con los años, las construcciones de esta manzanas sufrieron serias alteraciones, entre otras causas, por las Leyes de Reforma que afectaron a diversas propiedades e instituciones de carácter religioso debido a la desamortización de los bienes del clero, considerados en "manos muertas", por lo que pasaron a ser propiedad de la nación.

Por su lado el clero, ante la presencia de tales leyes, reaccionó en forma inmediata. En efecto, se llevó a cabo una serie de componendas (supuestas ventas, cambios ficticios de propietario, etc., etc.) con el objeto de salvar sus numerosos inmuebles (el 32 por ciento de las casas de Oaxaca pertenecían a la Iglesia), así como ciertos hechos para proteger los valores, particularmente joyas, de los conventos y templos. ${ }^{20}$

Pocas disposiciones legales pudieron haber tenido tantas repercusiones en la fisonomía de la ciudad como las causadas por dichas medidas. Las casas, los hospitales, las escuelas, las oficinas, las accesorias, los talleres y demás inmuebles pertenecientes al clero tanto seglar como regular debían ser adjudicadas a los particulares según el proceso administrativo correspondiente. Pero sucedió que muchos inquilinos, pese a haber vivido o trabajado en el inmueble tiempo atrás, incluso por generaciones, no se animaban a reclamar para sí un bien que consideraban propiedad de la Iglesia. Por otro lado, otros en las

19. Francisco José Ruiz Cervantes y Carlos Sánchez Silva, La ciudad de Oaxaca a través de sus planos, Oaxaca, Instituto Oaxaqueño de las Culturas-Universidad Autónoma Benito Juárez de Oaxaca-Instituto de Investigaciones en Humanidades, I 997.

20. Raúl Cruz Aguillón, Oaxaca nuestra ciudad, aspectos de su historia, Oaxaca, Honorable Ayuntamiento de Oaxaca de Juárez, I995, p. 98. 
mismas circunstancias y por supuesto menos escrupulosos aprovecharon las oportunidades para hacer negocios jugosos, incluso como prestanombres de algunos propietarios del clero. La concentración de bienes inmuebles pasó así de unas manos a otras, pero la movilidad desató cierta modernización y remodelación de la arquitectura civil, lo cual no sucedió con los templos y conventos que no pudo mantener el gobierno por la precariedad del erario y la inestabilidad, lo que los llevó a constituirse en edificios sin uso, "elefantes blancos" fantasmales que las más de las veces fueron cuarteles y arsenales.

Con respecto a la manzana frente a donde se ubica nuestra casa sede, sabemos que (en la sexta calle de Independencia se encontraba la Escuela Normal Mixta para Profesores en lo que había sido el Colegio de Niñas, institución para huérfanas fundada "por la mano generosa de [Manuel Fernández] Fiallo"), benefactor portugués de tiempos virreinales, al que le fueron afectadas 38 fincas entre I862 y I865 y quien ejerció pródigamente la caridad cristiana). Las fincas afectadas por la desamortización pertenecían al clero o a alguna de las numerosas agrupaciones laicas dedicadas a obras pías, como congregaciones, archicofradías, cofradías, capellanías y colegios, entre otras. ${ }^{21}$ Entre las propiedades desamortizadas se menciona la de las monjas capuchinas españolas, el monasterio de la Concepción, y el Santuario de Juquila. ${ }^{22}$ Posteriormente, en I884, la nomenclatura de las calles fue modificada.

\section{La casa de monseñor Eulogio Gregorio Gillow y Zavalza, arzobispo de Oaxaca}

La estabilidad y la reactivación económica del porfiriato generaron una movilidad de compraventa inmobiliaria muy dinámica y pronto las casas de la zona fueron requeridas por el clero debido, sin duda, a su cercanía con la catedral. Se sabe que la casa de avenida Independencia fue propiedad de la familia Fagoaga, ${ }^{23}$ así como de Joaquín Vasconcelos, hasta llegar a manos de José Zorrilla, acaudalado empresario textil, dueño de la Fábrica de Hilados y Tejidos Vista Hermosa ubicada en Etla. Zorrilla era vicecónsul de España y “constru-

\footnotetext{
21. Lira Vázquez, op. cit., p. I 37.

22. Véase "Bienes desamortizados...", op. cit.

23. La familia Fagoaga fue de hombres relevantes en la política y en las armas, como el caso del teniente coronel del regimiento de dragones Manuel María Fagoaga y de Juan Antonio Fagoaga. Véase Iturribaría, op. cit., pp. 28 y 29.
} 
yó en Oaxaca una de las casas porfirianas más lujosas; contaba además con cinco propiedades y era dueño de una planta eléctrica que daba servicio a una sección de la ciudad". 24

El ro de enero de i887 se realizó una operación de compraventa de la casa ubicada en avenida Hidalgo número 37, a través de un crédito hipotecario entre Zorrilla y el arcediano Hipólito Ortiz y Camacho, por la cantidad de Io 000 pesos; es decir, que dicha casa pasó abiertamente a manos del clero. ${ }^{25}$ En ese mismo año, el presidente Porfirio Díaz le pidió a Francisco Uriarte, en una carta escrita el 6 de agosto, una casa para albergar a Eulogio Gillow (véase "Anexo documental"), recién nombrado obispo de Antequera por el papa León XIII y consagrado episcopalmente en La Profesa el 3I de julio, con la asistencia de los representantes de sus padrinos, el mismo Díaz y su esposa Carmelita Romero Rubio.

El 9 de agosto, Natalio Parada le escribe al "Ilustrísimo señor doctor don Eulogio Gillow, digno obispo de Oaxaca", quien se encontraba en su hacienda de Chautla, lo siguiente:

Deseo vivamente que vuestra ylustrísima se conserve con buena salud [...] El seńor gobernador de la Mitra escribe y solo se ocupa de manifestarle a vuestra ylustrísima que la casa que fue de los Esperón no puede conseguirse y que el señor Pascual Portillo ofrece su casa para que la habite su señoría por el tiempo que guste desde su llegada, sin retribución alguna. La ofrece toda ajuarada, y los muebles son bastante buenos [...] También dice el señor Merlín que a él le parece que quedaría bien su señoría en la casa que habitaba el señor obispo Márquez, haciéndole algunas composturas. ${ }^{26}$

Gillow, por su parte, muestra interés por adquirir algunas casas frente a la alameda de León, "principalmente por la muy poca distancia con la catedral, pues entre otros propósitos tiene el de construir una bóveda subterránea que le permita pasar de la iglesia a su habitación sin cambiarse de uniforme $($ sic $) "{ }^{27}$

24. Lira Vázquez, op. cit., p. 343.

25. Archivo Histórico del Registro Público de la Propiedad del Estado de Oaxaca de Juárez, núm. reg. 62, io de enero de I 887.

26. Archivo Histórico de la Arquidiócesis de Antequera, Oaxaca, Fondo Diocesano, Sección Gobierno, Serie Correspondencia, 9 de agosto de 1887.

27. Archivo Histórico de la Universidad Iberoamericana, Colección Porfirio Díaz, caja I9, leg. I2, doc. 009088 , Io de septiembre de I 887 . 


\section{I 8}

JULIETA ORTIZ GAITÁN

El 25 de diciembre de I89I, el obispado de Oaxaca se erige en arzobispado, por lo que, tres años después,

el señor deán del Cabildo Eclesiástico de esta capital don Ignacio Merlín, el día nueve del presente mes de enero, ante el notario licenciado Juan Varela otorgó a favor del ilustrísimo arzobispo de esta arquidiócesis señor don Eulogio Gregorio Gillow y Zavalza, escritura de compra venta por la cantidad de siete mil pesos de la casa de que es dueño y poseedor marcada con el número 37 y situada en la sexta calle de avenida Independencia de esta ciudad. ${ }^{28}$

La casa colindaba, por entonces, con la de los herederos de Guadalupe García al oriente; al poniente, con la de la señora Monterrubio de Díaz (con una calle de por medio); al norte (también con una calle de por medio), con la de Juan Antonio Valle, y al sur, con otra casa del comprador, es decir, del propio Gillow. Se afirma en el Registro Público de la Propiedad:

La casa deslindada la hubo el vendedor por compra que de ella hizo al señor canónigo licenciado don Hipólito Ortiz y Camacho de esta vecindad, según consta en la escritura pública otorgada a su favor ante el notario público Juan Rey, vecino que fue de esta ciudad. [...] La casa vendida no está enajenada a distinta persona ni reporta gravamen de ninguna especie agregando que ya tenía entregado antes los títulos de la finca al comprador. [...] Los contratantes son de esta vecindad, solteros y ministros del culto católico, el vendedor es de setenta y un años de edad con domicilio en una casa de la cuarta calle de la avenida Independencia, el comprador de cincuenta y cuatro ańos de edad y vive en una casa de la segunda calle C.S. "Pascuas". El testamento fue presentado por el notario para su registro. Oaxaca de Juárez, enero once de mil ochocientos noventa y cuatro.

Rúbricas: Manuel Flores Castro

$$
\text { Alfonso Márquez (Secretario) }{ }^{29}
$$

La remodelación del Palacio Episcopal corrió a cargo de Gaspar Zapata, quien inicia los trabajos inmediatamente, según una carta que le envía el arzobispo Gillow donde menciona los pormenores de las obras, tanto de las que estaba

28. Archivo Histórico del Registro Público de la Propiedad del Estado de Oaxaca de Juárez, reg. núm. 72, I I de enero de I 894 .

29. Idem. 


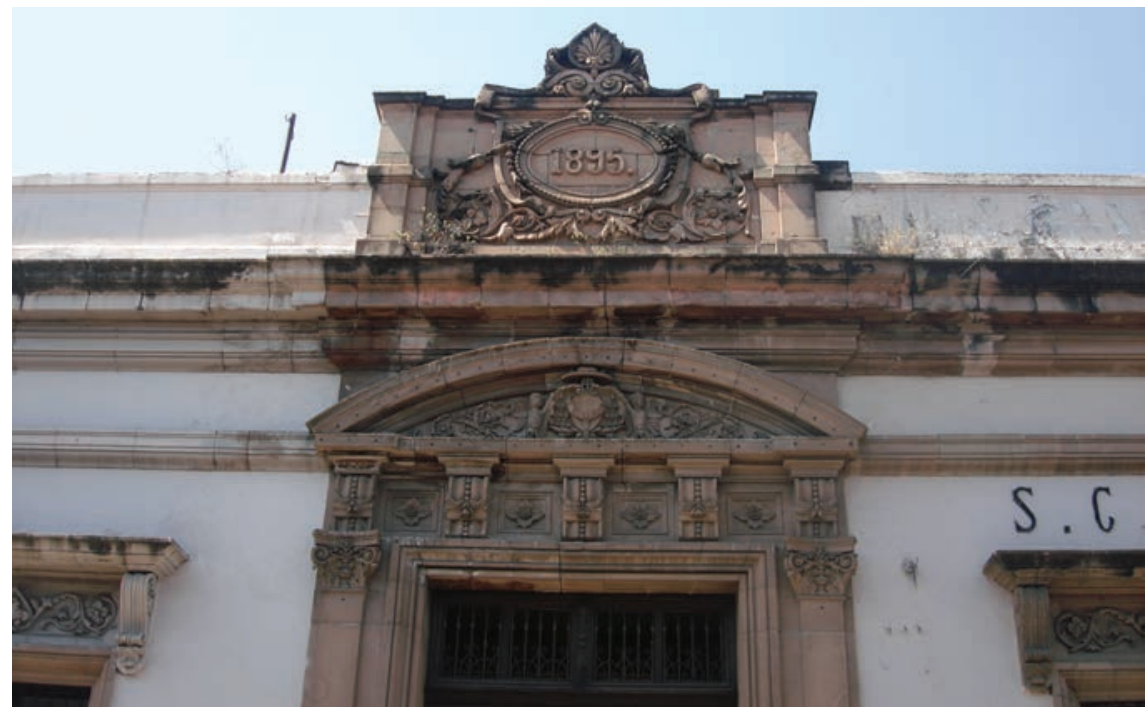

3. Portada del antiguo Palacio Arzobispal de Oaxaca, en la sexta calle de avenida Independencia. Conaculta-InAH-MÉx. "Reproducción autorizada por el Instituto Nacional de Antropología e Historia”. Foto: Marina Bayón, 2007. Archivo Fotográfico, Manuel Toussaint, IIE-UnAm.

realizando en dicho palacio como en el sagrario de la catedral. ${ }^{30}$ Se sabe que Juan de Castro también participó en los trabajos de esta remodelación y acondicionamiento de los recintos arzobispales ya que, al parecer, "por muchos años prestó sus servicios en ese ramo al arzobispo D. Eulogio Gregorio Gillow". ${ }^{\text {I }}$

La propiedad queda lista en I895, como lo indica el medallón labrado en el frontón curvo que corona la puerta principal, fecha en que monseñor se instaló en el flamante Palacio Episcopal. La construcción se erige sobre una estructura más antigua que adquirió un perfil de rasgos neoclásicos, resultado de las intervenciones y remodelaciones realizadas para la alta jerarquía eclesiástica a que estaba destinada. Muy acorde con la época, la casa tenía por entonces el estilo conocido coloquialmente como "francés".

30. Archivo Histórico de la Arquidiócesis de Antequera, Oaxaca, Fondo Diocesano, Sección Gobierno, Serie Correspondencia, 23 de octubre de I 894.

31. "Del momento actual, lo que ocurre en el solar oaxaqueño...", Oaxaca en México, 6 de febrero de I937, núm. I 5, p. I 5 apud Lira Vázquez, op. cit., p. 336. 
Las proporciones rectangulares de la puerta y las ventanas, muy altas, son totalmente diferentes a las del siglo XVıII; las ventanas tienen cornisas con ménsulas que limitan los dinteles ricamente esculpidos. La importancia de la entrada principal está marcada por cuatro ventanas a cada uno de los lados; sus pilastras, capiteles corintios, dinteles con ménsulas, la cornisa que sigue una línea continua, su frontón esculpido encerrado no por una cornisa caprichosa sino por un segmento curvo, todo esto es el compendio del neoclasicismo. ${ }^{32}$

En cuanto a la casa frente a la alameda de León, sabemos que los hermanos Manuel, Guadalupe y Francisca García vendieron por la cantidad de 3000 pesos a Andrés Portillo, el I de agosto de I889, la casa de bajos situada en la alameda de León esquina con la avenida Independencia, colindante al oriente con dicha alameda, al poniente con la del obispo diocesano, al norte con la de Juan Pablo Franco e Ignacio Esperón, por medio una calle, y al sur con la de Félix Romero. La escritura se registró el 25 de octubre de I891. ${ }^{33}$

En algún momento anterior a 1894, Gillow adquirió la propiedad colindante hacia el sur con los corrales de la casa de los Ortigosa, por lo que al comprar la casa destinada al Palacio Arzobispal, Gillow ya era propietario de una vasta casona con fachada a la calle de Hidalgo que ostenta un medallón sobre el dintel del alto portón con la fecha de i909. En este año se llevó a cabo la gran coronación de la Virgen de la Soledad, patrona de Oaxaca, cuya tiara estaba formada por las joyas de su madre, la marquesa de Selva Nevada; asimismo se celebró el IV Congreso Católico Nacional en la ciudad de Oaxaca, por lo que la inscripción agrega: "Recuerdo de la Coronación y IV Congreso. Enero I8, I909".

La casa presenta la apariencia de tantas otras que fueron comunes en nuestras ciudades y pequeñas poblaciones durante el siglo xıx. Son los años finiseculares los que imprimen un sello característico a la arquitectura civil de Oaxaca, como sucede en otras ciudades del territorio mexicano. La bonanza de las elites porfirianas propició la construcción de casas y edificaciones de relevancia dentro de esquemas impuestos por los requerimientos de un mundo cambiante, moderno e industrializado. De manera desigual y fragmentada, el impacto de todo ello llegó sólo a unos cuantos sectores y se refleja en formas sutiles del arte y la cultura. Podemos hablar, entre otras cosas, del carácter

32. Mullen, op. cit., p. I 56.

33. Registro Público de la Propiedad del Estado de Oaxaca, registro núm. I75, 25 de octubre de I 89I. 
ecléctico de la arquitectura finisecular, con una marcada tendencia hacia el estilo renacentista francés que, interpretado libre y abundantemente por nuestros arquitectos y constructores de casas, aportó los rasgos característicos de simetría, altura y sobria dignidad de la arquitectura civil del porfiriato.

"Una casa de altos y bajos ubicada en Oaxaca y marcada con el número 39 de la sexta calle de avenida Hidalgo y que mide io.30 metros lineales de frente y 46.35 metros lineales de fondo" estaba conformada, en avalúo hecho en 1917, por " 2 patios con 2 pisos y I6 piezas en el primer patio y dos pisos y 9 piezas en el segundo. Su construcción es de piedra y ladrillo, con 737.06 metros cuadrados de sitio que ocupa el edificio a razón de \$12.00 el metro [estos 9 I24.80 sólo por el terreno] la compra la Compañía Agrícola Industrial según avalúo". ${ }^{34}$ Los pavimentos eran de ladrillo y de loza, las bóvedas tipo "vastavina corriente y sencilla"; para los arquitrabes, frisos y cornisas, así como para los boceles de los pasillos, se había adquirido "labradura de piedra". El toque característico de la arquitectura finisecular lo daban las seis columnas de tubo de hierro con bases de piedra, empleadas seguramente para los corredores de algún patio interior; se mencionan pilastras de piedra, dos de ellas con capiteles y arcos de ladrillo. Se contaban 4I marcos de piedra, también labrada, para puertas y ventanas, así como i c copetes para las ventanas altas de la fachada con sus respectivas repisas. La casa contaba con 24 umbrales de piedra, tres escaleras de cemento y ladrillo, dos divididas en dos ramales y la otra con un solo ramal; "instalación sanitaria completa" que comprendía cinco "excusados" y tres "lababos" (sic); un estanque; 37 pares de puertas de madera; 25 puertas y vidrieras; un tragaluz; una puerta de calle; tres portones de fierro: uno grande, otro mediano y el último "censillo" (sic). Había rejas, balcones, barandales, dos "pies de gallo de fierro" y contramarcos de las puertas que daban a la calle con rejas chicas. Doce piezas estaban tapizadas con papel tapiz "censillo" y una mano de pintura; las bóvedas al óleo igual que el guardapolvo. El resto del edificio estaba pintado al temple y tenía un valor de 28500.00 pesos, seguramente de "plata de buen cuño".

Nota: Esta casa no está hipotecada y aparece actualmente registrada en el catastro con un valor de \$16 678.53.

34. Archivo General del Estado de Oaxaca, Manifestación de avalúo, número de catastro 2687 , I4 de julio de I9I7, f. 5 I. 
Presentada en la fecha y registrada bajo el número I657, folio 5 I del libro de registro respectivo. Oaxaca de Juárez, I4 de julio de I9I7. Rúbrica: P. Allende. ${ }^{35}$

Se trataba de una casa amplia, construida con materiales "sencillos", con abundante luz y aires refrescantes provenientes de los dos patios y numerosas piezas distribuidas en dos pisos, lo cual no era común en las casas de estirpe novohispana. Llama la atención la modestia de los materiales, ya que hasta las vidrieras y el tragaluz estaban hechos con "vidrios corrientes"; los primeros eran de "vidrio corriente, pintadas", por lo que no estaban manufacturados con la técnica más fina y cara del emplomado. Suponemos que el mobiliario de la casa debió ser más lujoso, pero no hay dato alguno al respecto. También es posible que, como en todo avalúo catastral, se minimicen los costos reales de la propiedad disminuyendo todo dato que pueda significar incremento de los impuestos.

Sabemos que en una parte del edificio que daba hacia la alameda se adaptaron unos baños públicos del mismo nombre y que las oficinas de Correos y Telégrafos se instalaron en la propiedad hacia mediados del siglo xIx. Sin embargo, para I909, el conjunto de casas y solares estaba cerrado por

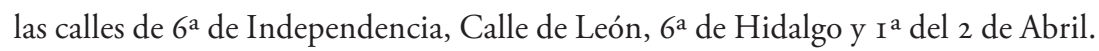
En el número 37 de la hoy $6^{a}$ de Independencia se encontraba una construcción "moderna" que era el Palacio Arzobispal, el propietario Monseñor E. G. Gillow y estaba valuada en 30000 pesos. En la hoy Calle de León, número I, una casa “antigua”, el Hotel Nacional, perteneciente a Tta. de Hahn (sic), con valor de 32000 pesos. ${ }^{36}$

En suma, Portillo señala que en I909 dicha manzana contenía cinco casas, tres "pertenecientes del Palacio Arzobispal" y especifica: "una casa antigua, una moderna. Total: 2 casas con 60 habitantes. Un hotel (la casa número I); y un palacio (la casa número 37 )".

35. Idem. El documento ostenta dos sellos de la Junta Calificadora del Catastro de la Municipalidad de Oaxaca, con fecha I 4 de julio de I9I7. Como encargado se nombra a Charles H. Arthiú, con domicilio en la avenida Hidalgo núm. 39.

36. Portillo, op. cit., s.p. 


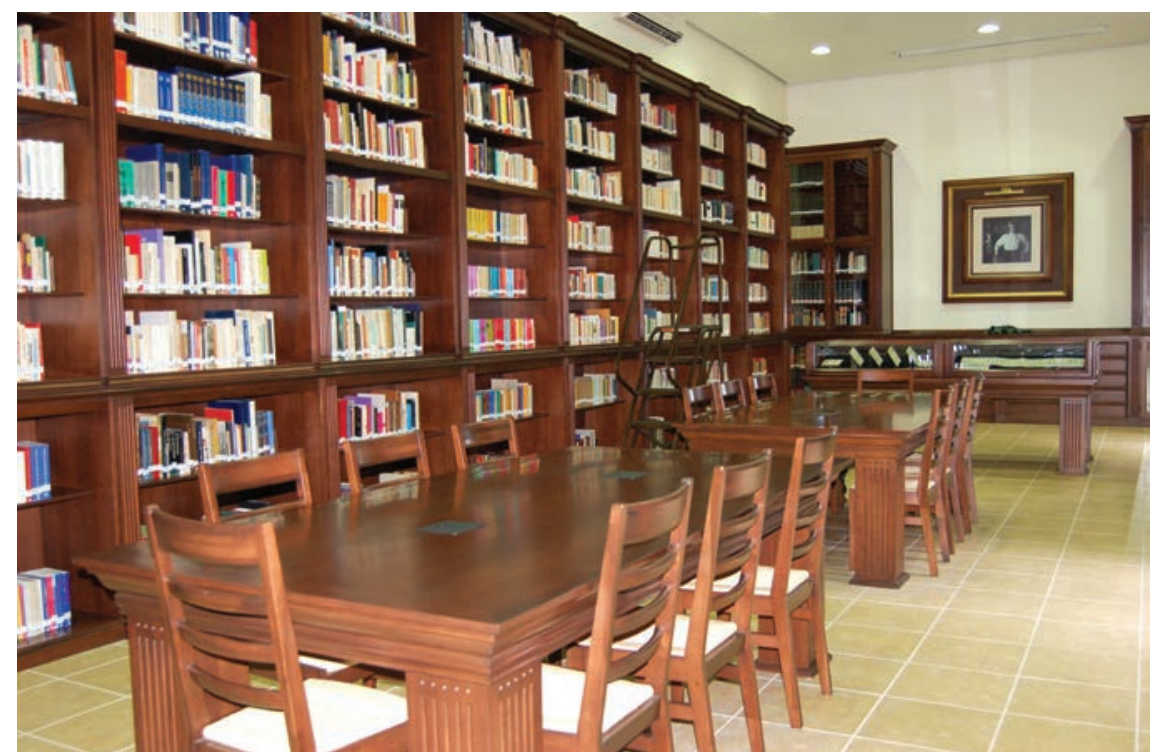

4. Sala de lectura de la Biblioteca Beatriz de la Fuente. Foto: Cecilia Gutiérrez, 2007, Archivo Fotográfico Manuel Toussaint, IIE-UnAm.

\section{Las preocupaciones de Gillow por los bienes terrenales}

La influencia de Gillow se aprecia en el desarrollo arquitectónico de la ciudad. Como ejemplo tenemos las remodelaciones que por su iniciativa se hicieron a la catedral y a los templos de Santo Domingo y San Juan de Dios, así como la reconstrucción del convento del Carmen Alto, por mencionar sólo algunas. La restitución de Santo Domingo fue, sin duda, uno de los mayores triunfos que obtuvo, en I895, de sus negociaciones con José Ives Limantour. La preocupación de Gillow por los bienes terrenales hizo que no sólo contribuyera a la remodelación y reconstrucción de los templos, sino que también fundara obras civiles como la ampliación del acueducto, la construcción del Seminario Diocesano a un costado de la catedral, en el centro mismo de la ciudad, y numerosas obras pías, como la casa de cuna instalada en el ex convento de San Agustín. Pero fue el Palacio Arzobispal, por supuesto, uno de tantos edificios que reconstruyó Gillow casi en su totalidad. Andrés Portillo lo describe como 
"casa notable ubicada en el no. 37 de la 6a calle de la Avenida Independencia, antes llamada del Colegio de Niñas". 37

Oaxaca, debido a la desamortización de los bienes eclesiásticos, vio modificada su traza colonial y sufrió una serie de cambios en cuanto a sus espacios urbanos y arquitectónicos, durante el tiempo que Porfirio Díaz ocupó la presidencia. Hoy, la ciudad de Oaxaca, a pesar de ser calificada como ciudad "colonial” presenta un porcentaje bastante alto de edificios decimonónicos y específicamente porfirianos. A lo largo de esta etapa algunas de sus construcciones virreinales fueron modificadas en gran medida. Unas cuantas fueron destruidas, otras transformadas para cubrir una función distinta a la original, muchas más se reconstruyeron después de haber sido afectadas por los constantes sismos. ${ }^{38}$

Ya consagrado arzobispo, Gillow continuó con una activa agenda de visitas pastorales a lo largo y ancho de la arquidiócesis, caracterizándose por sus frecuentes viajes a los más apartados rincones, donde sus feligreses veían cómo arribaba la numerosa caravana presidida por el alto dignatario — cargado en andas en una silla de viaje por algunos de sus fieles, quienes en ocasiones lo recibían con bandas de música, grandes festejos y muestras de entusiasmo-; pero también sucedía que no se aparecía alma alguna en poblaciones que apenas si sabían de su existencia, incluyendo al cura parroquial. Los textos de Cordilleras, así como el diario que Gillow escribió durante los 35 años que duró su misión, abundan en relatos interesantes y curiosos sobre las anécdotas variopintas de su grey.

Pero su intensa labor, principalmente de confirmaciones y catequesis, no impedía que Gillow atendiera activamente los asuntos de la jerarquía episcopal. En I893 organizó el Concilio Antequerense con la asistencia de las diócesis sufragáneas; y en marzo del mismo año consagró en la catedral de Oaxaca al primer obispo de Tehuantepec, José Mora y del Río, quien habría de cobrar relevancia y poder en los conflictos religiosos de los años veinte. Tampoco descuidó la cuestión social, particularmente efervescente por los aires revolucionarios que se anunciaban, y colaboró activamente en la creación del Círculo Católico de Obreros de Oaxaca en I904.

37. Ibidem, p. I 80 .

38. Lira Vázquez, op. cit., p. I7. 
El arzobispo Gillow no sólo se distinguió por su posición privilegiada entre los círculos de poder, sino también por haberse preocupado por el patrimonio histórico de la ciudad de Oaxaca. Defendió las propiedades de haciendas y latifundios, así como la devolución de los bienes expropiados al clero, como fue el caso del templo de Santo Domingo. Como asesor cercano a Porfirio Díaz, pudo dedicarse a la reforma de aquellas leyes lesivas para los intereses de la Iglesia y conservar así privilegios de clase, como los representados por su propia familia. Esta situación de bonanza y estabilidad, tanto en la vida de nuestro personaje como en la sociedad en general, perduró hasta I9I4, cuando el arzobizpo Gillow fue desterrado debido a las convulsiones revolucionarias. ${ }^{39}$ Todavía pudo festejar, dos años antes, el 25 aniversario de su jerarquía eclesiástica, ya que en un medallón que se encuentra en uno de los portones de los patios interiores se lee la siguiente inscripción:

3I de julio de I 887

25 Aniversario en la Celebración del Jubileo Episcopal del Illmo. y Rvmo. Sr. Arzobispo Dn. Eulogio Gillow

3I de julio de I9I2.

La posición política asumida por la sociedad y el gobierno de Oaxaca, en términos generales, fue de hostilidad y rechazo al gobierno surgido de la lucha revolucionaria de I9I0. Recordemos que fueron numerosas las muestras de júbilo que se dieron en el ámbito católico oaxaqueño a raíz de los sucesos de la Decena Trágica, ámbito ya de por sí polarizado desde los espinosos conflictos de la administración juarista y las Leyes de Reforma. La avanzada de la Iglesia, iniciada por León XIII, convocaba a cerrar filas contra doctrinas sociales de la época, como el comunismo, el socialismo, el anarquismo y otras que tanto intimidaban a los fieles católicos, orillándolos a intensificar por su parte la labor social de la Iglesia. Gillow, al igual que la alta jerarquía episcopal y la mayoría de los católicos, consideraba que sus bienes y derechos religiosos habían sido afectados desde las contiendas entre liberales y conservadores, pasando por las Leyes de Reforma y que, en I9Io, entraban a una nueva etapa de incertidumbre por las tensiones del estallido revolucionario. fuente de la historia, México, Centro inah Oaxaca, 2004. 
Por todo ello, la ciudad de Oaxaca celebró, con un entusiasmo, que "no tuvo límites" el cuartelazo de la Ciudadela. El padre Manuel de Jesús Ochoa le escribió a Gillow el 22 de febrero de I9I3, para narrarle cómo una multitud acudió al templo de Nuestra Señora de La Soledad a dar gracias a la Virgen por el cambio de gobierno y porque "había intercedido por la paz de la nación”. Esa vez, el Círculo Católico de Obreros organizó

una procesión cívica con faroles, música, cohetes y con las banderas y estandartes resultando una manifestación ordenada, decente, seria y sin gritos. Después hubo otra manifestación de seńoritas con antorchas, pero como se agregaron estudiantes y pueblo, hubo gritos de muera Madero y era la noche misma en que circuló la desgraciada muerte de los seńores Madero y Pino Suárez, digo la noticia de esa tragedia. Que Dios nuestro Señor haya perdonado a dichos señores. ${ }^{40}$

Pese al rumbo que tomaron los acontecimientos, Oaxaca continuó con la esperanza puesta en el nuevo orden social, ya que, según el padre Ochoa, "parece que el golpe de estado ha dado buen resultado, siempre los actos de energía infunden miedo y parece que así ha pasado esta vez pues no se sabe de nuevos levantamientos y la opinión va siendo más favorable al gobierno [de Huerta]". ${ }^{4}$

Un año después, el arzobispo Gillow ofició el matrimonio del hijo de Victoriano Huerta y la hija del general Juan A. Hernández, gobernador de Puebla. Preludio de ello fue que una vez que éste llegó a la presidencia, por la misma época, la Iglesia intensifica su acción y desafía públicamente al gobierno federal con la consagración que hace la grey católica a Cristo Rey, así como con la magna peregrinación a la Basílica de Guadalupe en la que el arzobispo Mora de la ciudad de México "pide perdón por los pecados de la nación". Quedan activadas desde entonces, I9I4, las bombas de tiempo que estallarían en la guerra de 1926 entre cristeros y gobiernistas, la llamada Cristiada que ensangrentó al país en los años veinte y treinta del siglo pasado. No es de extrañar, entonces, que Gillow y demás dignatarios eclesiásticos se vieran en la situación de un inminente exilio ante la caída de Huerta y el triunfo del Ejército Constitucionalista comandado por Venustiano Carranza.

40. Carta del padre Manuel de Jesús Ochoa a Gillow, 22 de febrero de I9I3, en Esparza, $o p$. cit., p. 46.

4I. Carta de Ochoa a Gillow, I7 de octubre de I9I3, en Esparza, op. cit., p. 47. 
Sin embargo, la influyente personalidad de Eulogio Gregorio Gillow fue sin duda un factor decisivo no sólo para el retorno a suelo mexicano con la reconciliación nacional de los años veinte, sino también para la recuperación de sus bienes materiales - recobrando su palacio de la avenida Independenciay su querida hacienda de Chautla, en Puebla, done había establecido una boyante empresa dedicada a la explotación y venta de pulque, la cual le dejaba jugosas ganancias que incrementaban su ya de por sí riquísimo patrimonio. Esta hacienda, al igual que otras de sus numerosas propiedades, habían pertenecido a su padre, Thomas Gillow, oriundo de Liverpool, quien había contraído matrimonio con María Josefa Zavalza y Gutiérrez, última marquesa de Selva Nevada; éstos heredaron los bienes del marquesado a su único hijo, Eulogio Gregorio, dejándole también la posición social privilgiada y los altos estratos de poder en que habían vivido. Por ello y por su gran capacidad para negociar con el gobierno civil fue requerido en el México difícil de la posrevolución y, a la edad de 80 años, en I92I, regresa a su patria en buenos términos con el presidente Álvaro Obregón y recupera su residencia en el Palacio Arzobispal de Oaxaca con buena parte de su menaje, libros y ornamentos.

Pero como bien sabemos, las glorias de este mundo son pasajeras y sólo vivió dos años después de este nuevo retorno, ya que el i8 de mayo de 1922 falleció en su última visita pastoral a Ejutla de Crespo. Había llegado en ferrocarril y tuvo la recepción tumultuosa que tanto le gustaba:

el mismo día estuvo confirmando. Se dice que a la hora de la comida oyó el "Dios nunca muere" que tocaba la banda; que todavía al irse a descansar pidió que lo tocaran por tercera vez. Esa tarde siguió confirmando a más de 300 niños. En la noche se empezó a sentir mal; el día I 6 siguió confirmando, esta vez a 80o. El I 7 todavía a otros 800 , pero ya se fue a dormir sintiéndose muy mal. El i 8 firmó con mano temblorosa su último auto de visita. Su último sermón, el del día de llegada a Ejutla, habló de los perjuicios del socialismo. ${ }^{42}$

Con él se extinguió la descendencia del marquesado de Selva Nevada y del conde de Yala. Irónicamente, al testar a favor de la Iglesia, sus bienes fueron restituidos como propiedad de la nación.

42. Manuel Esparza, Gillow durante el porfiriato y la revolución en Oaxaca (I887-I922), Oaxaca, s.e., I985, pp. I 85 y I 86 . 


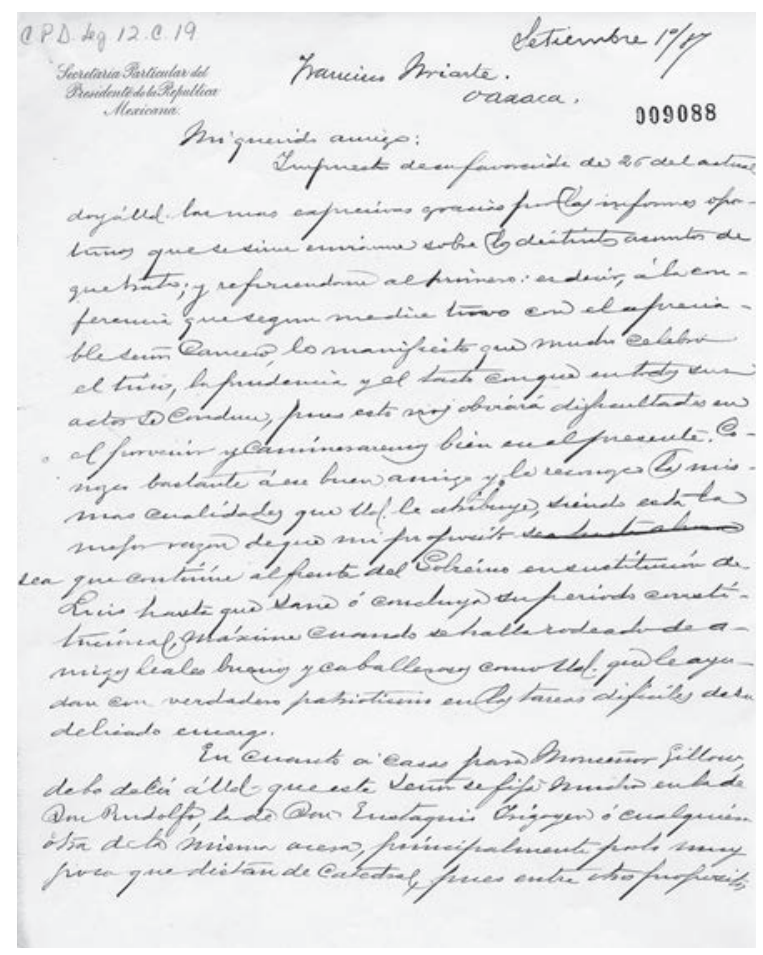

5. Carta de Porfirio Díaz a Francisco Uriarte, I de septiembre de I887, Archivo Histórico de la Universidad Iberoamericana, Colección Porfirio Díaz, caja I9, leg. I2, doc. 009088 , io de septiembre de 1887 .

En la actualidad, parte del edificio que ocupa nuestra casa sede funciona como oficina de Correos y Telégrafos. Desde I878, la oficina de Correos había ocupado una parte de una antigua casa solariega en el número 45 de la avenida Independencia, por ello llamada antes calle del Correo. "Tres empleados constituían su personal en aquellos años, siendo su administrador don Manuel Sáenz Pardo y sus dos únicos carteros don Juan Ramos y don Luis López”. 43 La oficina fue reinaugurada el 16 de octubre de 1968 por el presidente Gustavo Díaz Ordaz, según la placa colocada en la avenida 20 de Noviembre. Una oficina del Partido Revolucionario Institucional se estableció posteriormente

43. Ricardo Casanova C., "Breve historia del correo en Oaxaca", El Imparcial, Oaxaca, 30 de mayo de 1964 . 


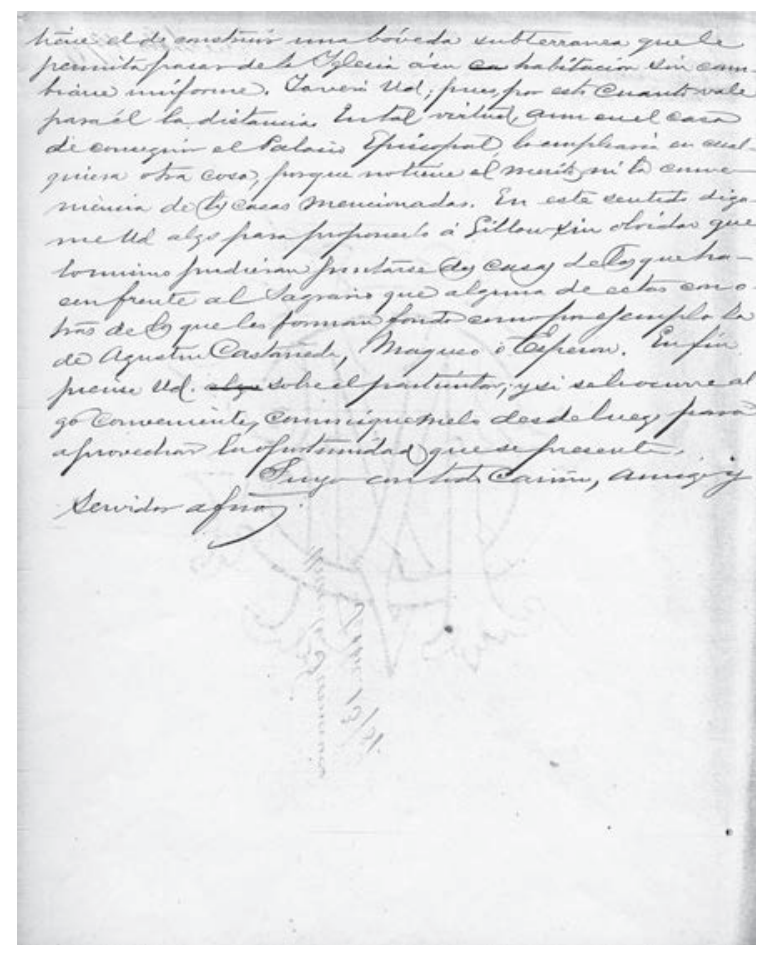

en el recinto y todavía se encontraba ahí en 2004.44 El I9 de marzo de 1976, el centro histórico de Oaxaca de Juárez fue declarado "zona de monumentos históricos”, y el 7 de diciembre de 1987 se le incluyó en la relación de Bienes del Patrimonio Mundial de la Humanidad de la unesco. ¿s

44. Esparza, Eulogio Gillow y el poder..., op. cit., p. I 25.

N.B. La investigación documental, realizada en los archivos de Oaxaca, estuvo a cargo de María del Carmen Sifuentes Rodríguez. 
Anexo documental

Secretaría Particular del

Presidente de la República

Mexicana

Francisco Uriarte.

Septiembre $\mathrm{I}^{\mathrm{o} / 87}$

Oaxaca.

Mi querido amigo:

Impuesto de su favorecida del 25 del actual doy a Ud. las más expresivas gracias por los informes oportunos que se sirve enviarme sobre los distintos asuntos de que trato; y refiriéndome al primero: es decir, a la conferencia que según me dice tuvo con el apreciable Señor Canseco, le manifiesto que mucho celebro el tino, la prudencia y el tacto con que en todos sus actos se conduce, pues esto nos obviará dificultades en el porvenir y caminaremos bien en el presente. Conozco bastante a su buen amigo y le reconozco las mismas cualidades que Ud. le atribuye, siendo ésta la mejor razón de que mi propósito sea que continúe al frente del Gobierno en sustitución de Luis hasta que sane o concluya su periodo constitucional, máxime cuando se halla rodeado de amigos leales buenos y caballerosos como Ud. que le ayudan con verdadero patriotismo en las tareas difíciles de su delicado encargo.

En cuanto a casas para Monseñor Gillow, debo decir a Ud. que este Señor se fija mucho en la de Don Rudolfo, la de Don Eustaquio Irigoyen ó cualquiera otra de la misma acera, principalmente por lo muy poco que distan de Catedral, pues entre otros propósitos tiene el de construir una bóveda subterránea que le permita pasar de la Yglesia a su habitación sin cambiarse uniforme. Ya verá Ud. pues, por esto cuánto vale para él la distancia. En tal virtud, aún en el caso de conseguir el Palacio Episcopal lo emplearía en cualquiera otra cosa, porque no tiene el mérito ni la conveniencia de las casas mencionadas. En este sentido dígame Ud. algo para proponerlo a Gillow sin olvidar que lo mismo pudieran juntarse dos casas de las que hacen frente al Sagrario que alguna de estas con otras de las que les forman fondo como por ejemplo la de Agustín Castañeda, Maqueo o Esperón. En fin piense Ud. sobre el particular, y si se le ocurre algo conveniente, comuníquemelo desde luego para aprovechar la oportunidad que se presente.

Suyo con todo cariño, amigo y servidor afectísimo

[Porfirio Díaz, sin rúbrica] 